HETEROCYCLES, Vol. 69, 2006, pp. 119 - 122. (C) The Japan Institute of Heterocyclic Chemistry

Received, 29th August, 2006, Accepted, 26th October, 2006, Published online, 27th October, 2006. COM-06-S(O)48

\title{
REACTION OF 2H-CYCLOHEPTA[b]FURAN-2-ONES WITH PYRIDINIUM SALTS OF TRIFLUOROMETHANESULFONIC ANHYDRIDE*
}

\author{
Noboru Morita, ${ }^{\mathrm{a} *}$ Tomohiro Matsuki, ${ }^{\mathrm{a}}$ Masashi Nakashima, ${ }^{\mathrm{a}}$ Taku Shoji, ${ }^{\mathrm{a}}$ \\ Kozo Toyota, ${ }^{\mathrm{a}}$ Shigeru Kikuchi, ${ }^{\mathrm{b}}$ and Shunji Ito ${ }^{\mathrm{c}}$ \\ a Department of Chemistry, Graduate School of Science, Tohoku University, \\ Sendai, 980-8578, Japan \\ morita@funorg.chem.tohoku.ac.jp \\ ${ }^{b}$ Graduate School of Science and Technology, Kumamoto University, Kurokami, \\ Kumamoto 860-8555, Japan \\ ${ }^{c}$ Department of Material Science and Technology, Faculty of Science and \\ Technology, Hirosaki University, Bunkyocho 3, Hirosaki 036-8561, Japan
}

\begin{abstract}
H-Cyclohepta[b]furan-2-one (1) reacted with TPT, electrophilically to give 3-dihydropyridinyl-2H-cyclohepta[b]furan-2-one and subsequent treatment with sodium hydroxide in ethanol gave 3-(4-pyridinyl)-2H-cyclohepta[b]furan2-one in excellent yields. Furthermore, it reacted with methyl iodide give a corresponding pyridinium salt easily.
\end{abstract}

2H-Cyclohepta[b]furan-2-one (1) ${ }^{1}$ and its derivatives have been well known as precursors of azulens. ${ }^{2}$ Their physical ${ }^{3}$ and chemical properties ${ }^{4}$ have received considerable attention due to their similar $\begin{aligned} & a: X=\mathrm{H}, b: X=B r, c: X=M e, \\ & d: X=\mathrm{CO}_{2} M e, e: X=C N\end{aligned}$
2 structures to azulenes and heptafulvenes. It is well-known that the 3-position of $\mathbf{1}$ has a high electron density like azulene and undergoes electrophilic substitutions such as formylation, acetylation, bromination and nitration. ${ }^{4}$ Recently, it was demonstrated that 2-oxo-2H-cyclohepta[b]furan-3-yl groups could stabilize some carbocations by extention of their $\pi$-electronic systems. ${ }^{5}$ Although some chemical properties of $\mathbf{1}$ have been clarified, ${ }^{4,5}$ it is not enough for the construction of new extended $\pi$-electronic systems. To develop a new binding procedure of two $\pi$-electronic systems is very important for functinalization and extension of $\pi$-electronic systems. We have reported the reactivities ${ }^{6}$ of azulenes with trifluoromethanesulfonylpyridinium trifluoromethanesulfonate (TPT) (3a), ${ }^{7}$ which is readily available from pyridine with trifluoromethanesulfonic anhydride $\left(\mathrm{Tf}_{2} \mathrm{O}\right)$ and has a high electrophilicity. We have also reported about our original synthetic way for $\mathbf{1}$ and its derivatives. ${ }^{8}$ In continuation of these studies, we investigated the reactivities of $\mathbf{1}$ with trifluoromethanesulfonic anhydride in the presence of pyridine and its derivatives, consistently. Here we report a new type of cross-coupling reaction for introduction to pyridinyl group to

\footnotetext{
${ }^{* \dagger}$ Dedicated to Professor Satoshi Omura occasion of his $70^{\text {th }}$ birthday.
} 
3-position of 1 without transition-metal catalysis.

After the reaction conditions of $\mathbf{1}$ with 3a were examined, we found a reaction product (4a) was obtained in good yields when the reaction was carried out as follows. A solution of $\mathbf{1}$ (1.521 g, $10.0 \mathrm{mmol})$ in dry dichloromethane $(20 \mathrm{~mL})$ was added to a solution of trifluoromethanesulfonic anhydride (5.645 g, 20.0 mmol) and dry pyridine (8.104 g, $101.8 \mathrm{mmol})$ in dry dichloromethane $(10 \mathrm{~mL})$ at $\mathrm{rt}$ in the period of 10 min under nitrogen atmosphere. It was stirring for $10 \mathrm{~h}$, reaction mixture was passed through column packed with dry $\mathrm{MgSO}_{4}$ and the solvent was removed under reduced pressure. The residue was separated by column chromatography on silica gel using the dichloromethane as an eluant to give a orange colored product 4a (3.241 g, $9.1 \mathrm{mmol}, 91 \%$ yield). The structure of $\mathbf{4 a}$ was established as 3-( $N$-trifluoromethanesulfonyl-1,4-dihydro-4-pyridyl)-2H-cyclohepta[b]furan-2-one by following spectra. Mass spectrum exhibits molecular ion peak at $\mathrm{m} / \mathrm{z}$ 357. The characteristic band for carbonyl group is observed at $1725(\mathrm{~s}) \mathrm{cm}^{-1}$ in the IR spectrum. Dihydropyridine ring protons appear at 6.64 (d, $J=7.8 \mathrm{~Hz}, 2^{\prime}$ '-, 6'-H), 5.07 (dd, J=7.8, 3.5Hz, 3'- 5'-H), 4.45 (bs, 4'-H) in ${ }^{1} \mathrm{H}$ NMR spectrum. The ring protons of 2H-cyclohepta[b]furan-2-one appear at 7.42 (d, $J=11.6 \mathrm{~Hz}, 4-\mathrm{H}), 7.07-6.98$ (m, 5-, 7-, and 8-H), 6.85 (t, $J=9.8 \mathrm{~Hz}, 6-\mathrm{H})$. The reaction proceed regiospecifically at 4-position of the pyridinium salt. We could not find a 2-position attack product. ${ }^{6}$ Another 3-substituted pyridinium salts (3b-e) react similarly with $\mathbf{1}$ to give corresponding $2 H$-cyclohepta[b]furan-2-ones (4b-e) as shown in Table 1.

\begin{tabular}{cccc}
$\begin{array}{r}\text { Table1. Reaction of } \mathbf{1} \text { with 2a-e and trifluoromethanesulfonic anhydride } \\
\text { Entry }\end{array}$ & $\begin{array}{c}\text { Substituted pyridines } \\
\text { Yields of } \mathbf{4}\end{array}$ & $\begin{array}{c}\text { mp }\left({ }^{\circ} \mathrm{C}\right) \\
\mathbf{( \% )}\end{array}$ \\
\hline 1 & $\mathrm{H}$ & 91 & $136-137$ \\
2 & $\mathrm{Br}$ & 40 & $134-135$ \\
3 & $\mathrm{CH}_{3}$ & 49 & $109-110$ \\
4 & $\mathrm{CO}_{2} \mathrm{CH}_{3}$ & 78 & 167 (decomp.) \\
5 & $\mathrm{CN}$ & 100 & 176 (decomp.)
\end{tabular}

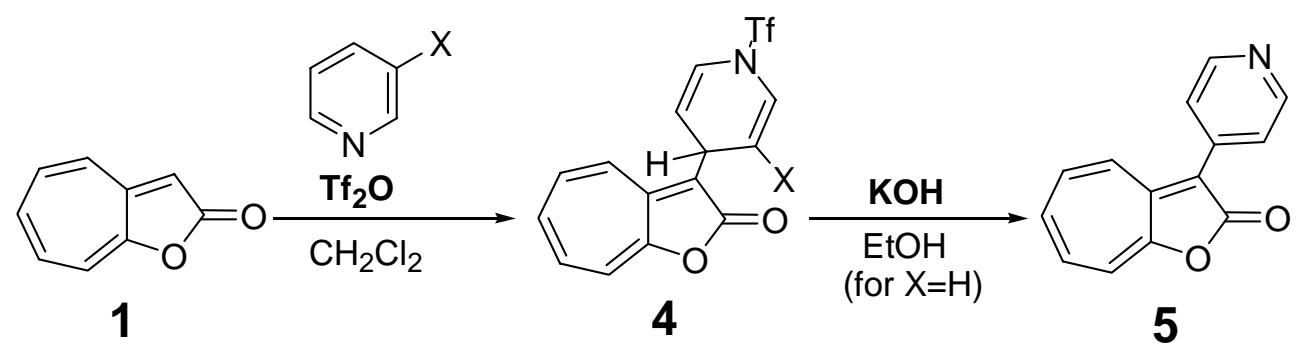

The dihydropyridine (4a) was treated with 3 equiv. of potassium hydroxide in ethanol to give 3-(4-pyridyl)-2H-cyclohepta[b]furan-2-one (5) in 64.3\% yield as orange solid (mp 243.8-245.4 ${ }^{\circ} \mathrm{C}$ (decomp.)) through the dissociation of trifluoromethane sulfinic acid. The methine proton of $\mathbf{4 a}$ at 4.45 ppm was disappered in ${ }^{1} \mathrm{H}$ NMR of 5 and pyridyl ring protons of 5 appeared at $\delta 8.71$ (dd, 2H, $J=4.4$, $1.6 \mathrm{~Hz}$ ) and $7.60(\mathrm{dd}, 2 \mathrm{H}, J=4.4,1.6 \mathrm{~Hz})$. Another $2 \mathrm{H}$-cyclohepta[b]furan-2-one ring protons appear at 
$7.71(\mathrm{~d}, 1 \mathrm{H}, J=11.6 \mathrm{~Hz}, 4-\mathrm{H}), 7.19$ (dd, $1 \mathrm{H}, J=11.6,8.4 \mathrm{~Hz}, 5-\mathrm{H}), 7.15-7.11(\mathrm{~m}, 2 \mathrm{H}), 6.97$ (dt, $1 \mathrm{H}, J=$ 8.4, $6.4 \mathrm{~Hz}, 6-\mathrm{H})$. The $\lambda_{\max }\left(\log \varepsilon\right.$ ) of the longest wavelength of 5 is 404 (4.12) in $\mathrm{CH}_{2} \mathrm{Cl}_{2}$, which is shifted to longer wavelength due to the contribution of pyridine ring as compared with $\mathbf{1}$. Reaction of 5 with methyl iodide gave a pyridinium salt (6) in 93\% as orange solid (mp 272.0-272.5 ${ }^{\circ} \mathrm{C}$ (decomp.)), whose ${ }^{1} \mathrm{H}$ NMR (400 MHz, CD $3 \mathrm{CN}$ ) shows at $\delta 8.53$ (d, 2H, $J=6.8 \mathrm{~Hz}, 2^{\prime}$, 6'-H), 8.36 (d, 2H, $J=6.8 \mathrm{~Hz}, 3^{\prime}$, 5'-H), 8.18 (d, 1H, $J=11.2$ Hz, 4-H), 7.74 (dd, 1H, $J=11.2,9.2$ Hz, 5-H), 7.66-7.65 (m, 2H), 7.50-7.45

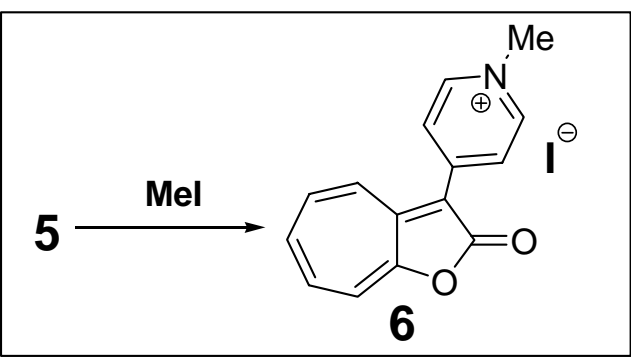
(m, 1H), and $4.22(\mathrm{~s}, 3 \mathrm{H})$. The UV-vis spectrum of 6 shows $\lambda_{\max }$, nm (log $\varepsilon)$ at 236 (4.38), 251 (4.43), 324 (3.81) and 454 (4.44). To compare the positions of $\lambda_{\max }$ of $\mathbf{1}, \mathbf{4 , 5}$ and $\mathbf{6}$ in the longest wavelengths, their positions change to longer wavelength in order of $\mathbf{1}<\mathbf{4}<\mathbf{5}<\mathbf{6}$. On the basis of these results, the cationic charge of $\mathbf{6}$ was delocalized to oxaazulanone ring by the contribution of $\mathbf{6}^{\prime}$ and $\mathbf{6}$ ” structures.

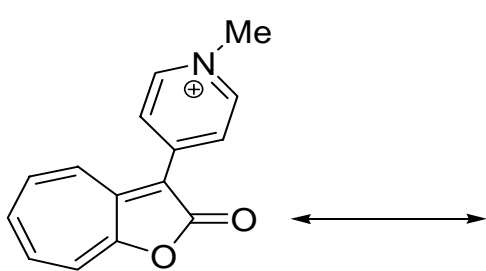

6

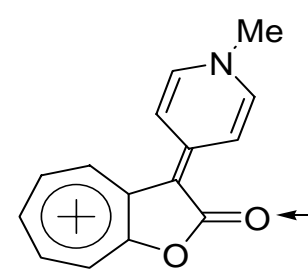

6'

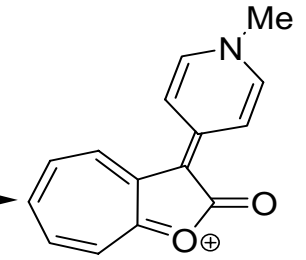

6"

In summary, a simple new procedure for the preparation of $\mathbf{5}$ and its salt (6) from $\mathbf{1}$ has been succeeded. Investigation into the scope and application of this methodology for the synthesis of 3-heteroaryl-2H-cyclohepta[b]furan-2-one is currently under way in our laboratories.

\section{REFERENCES AND NOTES}

1. S. Seto, Sci. Rep. Tohoku University, First Series, 1953, 37, 367.

2. a) T. Nozoe, S. Sto, S. Matumura, and T. Terasawa, Chem. Ind., 1954, 1356. b) T. Nozoe, K. Takase, and N. Shimazaki, Bull. Chem. Soc. Jpn., 1964, 37, 1644. c) T. Nozoe, K. Takase, T. Nakazawa, and S. Fukuda, Tetrahedron, 1971, 27, 3357. d) T. Nozoe, K. Takase, M. Kato, and T. Nogi, Tetrahedron, 1971, 27, 6023. e) P.-W. Yang, M. Yasunami, and K. Takase, Tetrahedron Lett., 1971, 12, 4275.

3. a) Y. Sasada, Bull. Chem. Soc. Jpn., 1959, 32, 165. \& 171. b) Y. Kurita and M. Kubo, J. Am. Chem. Soc., 1957, 79, 5460.

4. See, e.g: a) T. Nozoe, Cromatica Chimica Acta, 1957, 29, 207. b) T. Nozoe Asakurashoten, Tokyo 1960, Daiyukikagaku Vol. 13, pp. 535-608.

5. a) S. Naya and M. Nitta, J. Chem. Soc., Perkin Trans. 1, 2000, 2777. b) S. Naya and M. Nitta, J. Chem. Soc., Perkin Trans. 2, 2000, 2427. c) S. Naya and M. Nitta, J. Chem. Soc., Perkin Trans. 2, 2001, 275. d) S. Naya, T. Sakakibara, and M. Nitta, J. Chem. Soc., Perkin Trans. 2, 2001, 1032. e) S. Naya, M. Isobe, Y. Hano, and M. Nitta, J. Chem. Soc., Perkin Trans. 2, 2001, 2253. f) S. Naya and M. Nitta, Tetrahedton, 2003, 59, 4157. g) S. Naya, T. Watano, and M. Nitta, Bull. Chem. Soc. Jpn., 2003, 76, 2035. h) S. Naya, K. Yoda, and M. Nitta, Tetrahedron, 2004, 60, 4953. i) S. Naya, K. Yoda, and M. Nitta, Tetrahedron, 2005, 61, 8616.

6. S. Ito, R. Yokoyama, T. Okujima, T. Terazono, T. Kubo, A. Tajiri, M. Watanabe, and N. Morita, Org. Biomol. Chem., 2003, 1, 1947.

7. R. A. Toscano, M. C. Hernándes-Galindo, R. Rosas, O. García-Mellando, F. R. Portilla, C. 
Amábile-Cuevas, and C. Álvarez-Toledano, Chem. Pharm. Bull., 1997, 45, 957. 8. N. Morita, M. Kudo, R. Yokoyama, and S. Ito, Heterocycles, 2001, 54, 679.

9. A. R. Katritzky, S. Zhang, and T. Kurz, and M. Wang, Org. Lett., 2001, 3, 2807. 